\section{The knee joint loose body as a source of viable autologous human chondrocytes}

\section{J. Melrose ${ }^{1,2,3}$}

${ }^{1}$ Raymond Purves Bone and Joint Research Laboratory, Kolling Institute Northern Sydney Local Health District, St. Leonards

2Sydney Medical School, Northern, University of Sydney, Royal North Shore Hospital

${ }^{3}$ Graduate School of Biomedical Engineering, University of New South Wales, Kensington, Australia

\section{Abstract}

Loose bodies are fragments of cartilage or bone present in the synovial fluid. In the present study we assessed if loose bodies could be used as a source of autologous human chondrocytes for experimental purposes. Histochemical examination of loose bodies and differential enzymatic digestions were undertaken, the isolated cells were cultured in alginate bead microspheres and immunolocalisations were undertaken for chondrogenic markers such as aggrecan, and type II collagen. Isolated loose body cells had high viability ( $\geq 90 \%$ viable), expressed chondrogenic markers (aggrecan, type II collagen) but no type I collagen. Loose bodies may be a useful source of autologous chondrocytes of high viability.

\section{Introduction}

Loose bodies (also known as rice bodies and knee joint mice) are fragments of cartilage or bone that float freely within the synovial fluid component of the knee joint. They may occur in single or multiple forms ${ }^{1}$ but generally only affect a single knee. Loose bodies are classified as either stable or unstable. The former are located in fixed positions in the knee and are generally well tolerated and asymptomatic while the latter are free to move around the knee joint and may be the cause of pain, knee joint swelling, joint weakness and may cause the knee to lock abruptly. Loose bodies have a traumatic origin such as dislocation of the patella $^{2}$ or a complication arising from an orthopaedic procedure ${ }^{3-5}$ and their occurrence is more likely in patients affected by osteoarthritis (OA) or rheumatoid arthritis (RA). Smooth bodies are classified as fibrinous, cartilaginous and osteocartilaginous.
Fibrinous loose bodies result from intra-articular bleeding or by death of synovial tissue associated with tuberculosis, OA or RA. Cartilaginous loose bodies are caused by traumatic injury to the $\mathrm{OA}$ joint. Osteocartilaginous loose bodies are caused by fractures, osteochondritis dissecans, ${ }^{6,7}$ inflammation, synovial chondromatosis ${ }^{7}$ or tumours (osteochondromas). ${ }^{8,9}$ Loose bodies are normally small, ${ }^{9}$ but cases of giant loose bodies have also been reported. ${ }^{8}$

In the present study histological examination of loose bodies showed to our surprise that they were highly cellular containing large numbers of viable chondrocytes and suggested that they may be a potential source of autologous human chondrocytes for repair strategies. We subsequently went on to isolate this chondrocyte population, they displayed high viability and were highly proliferative compared to chondrocytes isolated from residual tibial and femoral articular cartilage from the same knee joint replacements. The loose body chondrocytes expressed type II collagen, aggrecan and 5D4 KS in 3D alginate bead culture but no detectable type I collagen.

\section{Materials and Methods}

All chemicals and supplier details are as previously indicated described. ${ }^{10,11}$ Monoclonal antibodies to aggrecan (clone 4D11 2A9), type I collagen (clone I-8H5), type II collagen (clone II-4CII), biotinylated anti-mouse IgG and antirabbit IgG secondary antibody, horseradish peroxidase conjugated streptavidin have been described previously. ${ }^{10,12}$

\section{Tissues and cells}

Loose bodies harvested from total knee replacement surgical discards from 6 patients (median age 56 years, 3 male, 3 female) of the Orthopaedics Clinic at North Shore Private Hospital, St. Leonards, were obtained with informed consent under ethical approval of the human ethics and care committee of the Royal North Shore Hospital who approved all procedures.

\section{Isolation and culture of chondro- cytes from the loose bodies}

Chondrocytes were enzymatically isolated from loose bodies by sequential digestion with: i) $0.1 \%(\mathrm{w} / \mathrm{v})$ pronase in DMEM-F12 media containing $10 \%(\mathrm{v} / \mathrm{v}) \mathrm{FCS}$ for $2 \mathrm{~h}$ at $37^{\circ} \mathrm{C}$; ii) $0.05 \%(\mathrm{w} / \mathrm{v})$ clostridial collagenase in media for $4 \mathrm{~h}$; and iii) overnight digestion with collagenase. ${ }^{11}$ The cells were spun down (10 min $\mathrm{x}$ $800 \mathrm{~g})$ and cell viability and numbers determined on a haemocytometer using trypan blue exclusion. Examination of the front and side
Correspondence: Dr. James Melrose, Raymond Purves Bone and Joint Research Laboratories, Institute of Bone and Joint Research, Level 10, Kolling Institute, B6, The Royal North Shore Hospital, St. Leonards, NSW 2065, Australia. Tel. +61.2.9926-4806 - Fax: +61.2.9926-5622. E-mail: james.melrose@sydney.edu.au

Key words: Loose body; human chondrocytes; total knee arthroplasty, repair medicine.

Conflict of interest: the author reports no conflicts of interest or financial disclosures.

Acknowledgements: Funding for this study was provided by NHMRC Project Grant 104032 . NHMRC took no part in conceptualising, implementing or had in-put into experimental design or interpretation of experimental data, these were the full responsibility of the author. Ms. Susan Smith (Raymond Purves Laboratory, Kolling Institute, Royal North Shore Hospital) is gratefully acknowledged for conducting the expert histological procedures described in the present study.

Received for publication: 24 March 2016. Accepted for publication: 5 May 2016.

This work is licensed under a Creative Commons Attribution-NonCommercial 4.0 International License (CC BY-NC 4.0).

(C) Copyright J. Melrose, 2016

Licensee PAGEPress, Italy

European Journal of Histochemistry 2016; 60:2645 doi:10.4081/ejh.2016.2645

scatter characteristics of these cells by flowcytometry was similar to results obtained earlier with only one major cell population evident. ${ }^{11}$ The cells were established in monolayer culture in $75 \mathrm{~cm}^{2}$ canted neck flasks at a density of 100,000 cells/mL in DMEM-F12 + $10 \%$ FCS + antibiotics under an atmosphere of $5 \% \mathrm{CO}_{2}$ and $98 \%$ humidity at $37^{\circ} \mathrm{C} .{ }^{11}$ After cellular attachment overnight, the flasks were rinsed in PBS to remove non-adherent cells and cultured in DMEM-F12 media $+10 \%$ FCS + antibiotics, with media changes every 3 days. The cells became confluent on day 5-6, the cells were sub-cultured up to passage 9 .

\section{Preparation and culture of loose body cells in calcium alginate beads}

The loose body cells from one $75 \mathrm{~cm}^{2}$ canted neck flask were detached using trypsin-EDTA and pelleted $(800 \mathrm{~g} \times 10 \mathrm{~min})$ then washed in sterile DMEM-Hams Fl2 + 10\% v/v FCS and resuspended in $2 \mathrm{~mL}$ of DMEM-Hams Fl2-FCS. Cell numbers and viability assays were measured on an aliquot using a haemocytometer and trypan blue exclusion. A known number of cells (95\% viability) were spun down again and 
dispersed at a density of $3 \times 10^{6}$ cells/mL alginate in sterile isotonic saline. This mixture was loaded into a $2 \mathrm{~mL}$ syringe and extruded drop-wise through a 23 guage needle into an agitated solution of sterile $\mathrm{CaCl}_{2}(102 \mathrm{mM})$ in a laminar flow hood to maintain sterility. After 10 min curing time the calcium alginate beads $(\sim 10 \mathrm{~mL} / 30,000$ cells $)$ were established in culture in small petri dishes (100 beads/plate) in DMEM-F1 $+10 \%$ FCS + $50 \mu \mathrm{g} / \mathrm{mL}$ ascorbic acid ( $5 \mathrm{~mL}$ media/plate). The plates were incubated at $37^{\circ} \mathrm{C}$, in an atmosphere of $5 \% \mathrm{CO}_{2}$ in air, with a humidity of $98 \%$ and the medium replenished every $48 \mathrm{~h}$. The loose body cells were cultured up to 4 weeks and samples of beads collected after 2,3 and 4 weeks of culture as indicated earlier. ${ }^{11,13,14}$ The remaining beads were rinsed in isotonic saline and solubilized in $55 \mathrm{mM}$ trisodium citrate in $150 \mathrm{mM}$ $\mathrm{NaCl}(2 \mathrm{~mL} / 50$ beads) and the cells spun down at $800 \mathrm{~g} \mathrm{x} 10 \mathrm{~min}$. The cells were then either cryopreserved in liquid nitrogen or were reestablished in monolayer culture.

\section{Histological processing of alginate beads}

Beads were fixed $3 \mathrm{~h}$ in $10 \%(\mathrm{v} / \mathrm{v})$ formalin, $85 \%(\mathrm{v} / \mathrm{v})$ ethanol, $5 \%(\mathrm{v} / \mathrm{v})$ acetic acid transferred overnight into $70 \%(\mathrm{v} / \mathrm{v})$ ethanol and embedded in paraffin then sectioned at $4 \mu \mathrm{m}$ thickness and attached to SuperFrost ultraPlus positively charged microscope slides. The slides were de-paraffinised in xylene (2 changes $\mathrm{x} 5 \mathrm{~min}$ ), re-hydrated through graded ethanol washes $(100-70 \% \mathrm{v} / \mathrm{v})$ to water.

\section{Histochemistry}

Bead and loose body sections $(4 \mu \mathrm{m})$ were stained for $10 \mathrm{~min}$ with $0.04 \%(\mathrm{w} / \mathrm{v})$ toluidine blue in $0.1 \mathrm{M}$ sodium acetate buffer, $\mathrm{pH} 4.0$ followed by a 2 -min counterstain in $0.1 \%(\mathrm{w} / \mathrm{v})$ fast green FCF. Sections were also stained in Mayers Haematoxylin (5 min), rinsed in tap water blued in Scotts Blueing solution (1 min) and counterstained in $0.0001 \%(\mathrm{w} / \mathrm{v})$ eosin (5 $\min )$.

\section{Immunolocalisation of type I and type II collagen, aggrecan and keratan sulphate}

Endogenous peroxidase was blocked in bead samples with $0.3 \%(\mathrm{v} / \mathrm{v}) \mathrm{H}_{2} \mathrm{O}_{2}$ for 10 min then blocking undertaken in DAKO non-protein blocking agent. Aggrecan immunolocalisation were pre-digested with chondroitinase $\mathrm{ABC}(0.1$ $\mathrm{U} / \mathrm{mL}$ ) in $50 \mathrm{mM}$ Tris $\mathrm{HCl} \mathrm{pH} 7.2+2 \%$ (w/v) BSA for $1 \mathrm{~h}$, type I and II collagen immunolocalisations were pre-digested with proteinase $\mathrm{K}$ for 6 min and bovine testicular hyaluronidase (1000 $\mathrm{U} / \mathrm{ml}$ ) for $1 \mathrm{~h}$ at $37^{\circ} \mathrm{C}$ in phosphate buffer $\mathrm{pH} 5.0$. The bead sections were incubated with antiaggrecan (1/10,000 dilution), anti-type I collagen (1/300 dilution), anti type II collagen (1/200 dilution) and MAb 5-D-4, anti-KS (1/1000 dilution) in TBS $+2 \%(\mathrm{w} / \mathrm{v})$ BSA overnight at $4^{\circ} \mathrm{C}$ then biotinylated anti-mouse and anti-rabbit IgG antibodies and horse-radish peroxidase conjugated streptavidin were added using Nova RED substrate for visualisation. Negative control sections were run omitting primary $\mathrm{Ab}$ or using an irrelevant primary antibody. Both yielded negative results. The stained specimens were examined using a Leica photomicroscope linked to a DFC 480 digital camera using brightfield illumination.

\section{Results}

Loose bodies were observed in 12 of 18 total knee joint replacements, and typically 2-5 mm in size, smooth and glistening. Histological examination demonstrated a high cell density and abundant deposition of proteoglycan in the loose bodies (Figure 1). The loose body contained a central necrotic core where the cells were arranged in clumps. Closer inspection within the loose body sections revealed a tran-

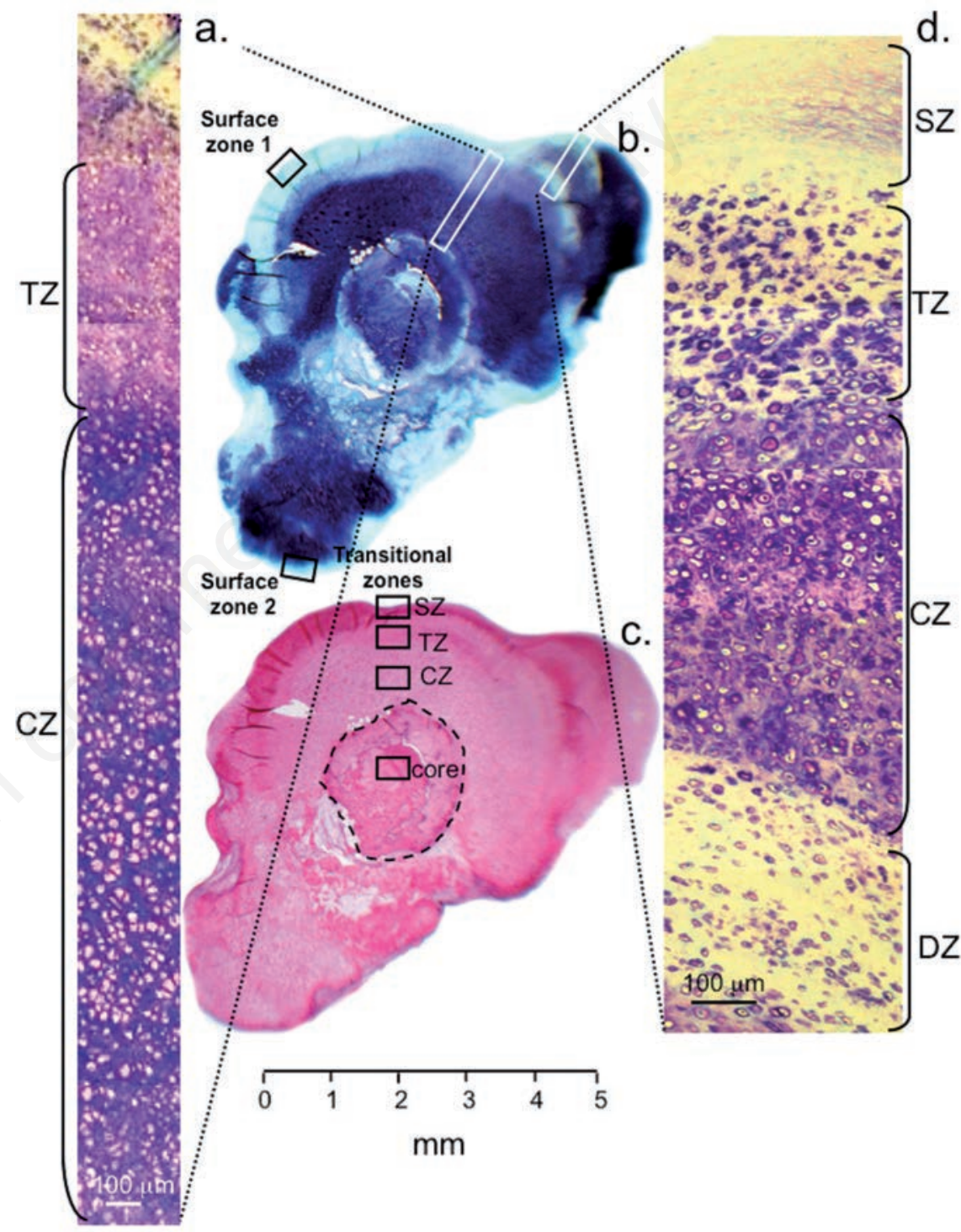

Figure 1. Composite figure depicting cellular morphologies in two indicated areas of the loose body $(\mathrm{a}, \mathrm{d})$. A central core is discernable in the toluidine blue-fast green and H\&E stained macroscopic views of the loose body $(b, c)$. Various areas of the loose body are presented at higher magnification elsewhere in this manuscript, these are indicated as boxed areas, surface zone 1,2 and transitional zones. The tissue slices contain cartilaginous cells of differing morphologies in the transitional zone (TZ) to the more rounded cells of the cartilaginous zone $(\mathrm{CZ})$ while deep zone $(\mathrm{DZ})$ cells are similar to the TZ cells. The surface zone (SZ) cells are of a flattened morphology, are smaller and do not express proteoglycan. 
sition in cell morphology and tissue organisation from the surface zones into the transitional zone through to the cartilaginous and necrotic core (Figure $1 \mathrm{a}, \mathrm{d}$ ). The surface zone region contained a population of flattened fusiform cells in a fibrous matrix overlying a mixed population of cells of a rounded chondrocyte like morphology (Figure 2a). This led into the transitional zone where larger chondrocyte-like cells were also evident (Figure 2b). The cartilaginous zone contained closely packed large chondrocyte-like cells (Figure 2c). The central core contained clumps of cells, many were dead or necrotic and many of the lacunae were unoccupied in the tissue sections examined (Figure 2d). Examination of surface zone 1 revealed stratification of the cells into three discernable zones, two surface zone regions containing cells of a flattened morphology but little proteoglycan (Figure 2f), and a cartilaginous zone underlying this containing a dense population of rounded chondrocyte like cells surrounded by metachromatically stained proteoglycan (Figure 2g). Surface zone 2 displayed similar traits to surface zone 1 with a surface fibrous region containing flattened cells overlying a cartilaginous zone containing larger chondrocytes in a proteoglycan rich matrix (Figure $2 \mathrm{~h}, \mathrm{i}$ ).

Examination of the front and side scatter characteristics of the chondrocytes released from the loose bodies by flow-cytometry showed only one cell population (Figure 3a). A small proportion of dead/non-viable cells was also evident however these did not attach during the expansion of cell numbers by monolayer culture. Morphometric image analysis of bead sections immunolocalised for type I and II collagen and aggrecan demonstrated a steady increase of these components in the alginate beads over 2-4 weeks in culture (Figure 4 b,c). Type I collagen was not expressed by rounded chondrocyte-like loose body cells in alginate bead culture (Figure 4a) however it was produced by a few $(<5 \%)$ cells of a flattened morphology at the bead surface after 4 weeks of bead culture. These expressed low levels of type I collagen (Figure 4e) but did not express type II collagen (Figure 4f). Comparative immunolocalisation of type II collagen (Figure 4b), aggrecan (Figure 4c) and KS (Figure 4d) produced by the central rounded loose body cells in 28 days of alginate bead culture clearly established their pedigree as a chondrogenic cell type.

\section{Discussion}

The present study arose from a series of failed attempts to isolate articular chondrocytes from the articular remnants of discarded surgical material from total knee arthroplasty patients. This was not an unexpected finding given that these specimens had little residual cartilage, displayed severe eburnation, loss of $>50 \%$ of the menisci and marginal osteophytic features of advanced knee-joint degeneration. The chondrocytes that were isolated typically were $50-60 \%$ viable, had poor replicative capability, and were obtained in insufficient numbers to warrant further investigation. Incidental observations on a number of these knee replacement tissues drew our attention to small glistening loose bodies present in a significant number of cases (12/18). On closer inspection histologically we were surprised to see that the loose bodies were highly cellular and contained abundant proteoglycan, the same could not be said of the residual articular cartilage of these joints. A necrotic core was a common finding particularly in the loose bodies $\geq 4 \mathrm{~mm}$ in size however this was to be expected given the advanced degenerative features of these knee specimens. We subsequently developed a protocol to isolate the loose body chondrocytes at $\geq 95 \%$ viability.

The therapeutic use of autologous chondrocytes in isolation ${ }^{15}$ or in combination with mesenchymal stem cells ${ }^{16}$ in the development of cartilage repair strategies are of considerable interest in repair medicine. ${ }^{17}$ The present study describes a simple convenient procedure for the isolation of these cells from loose bod-
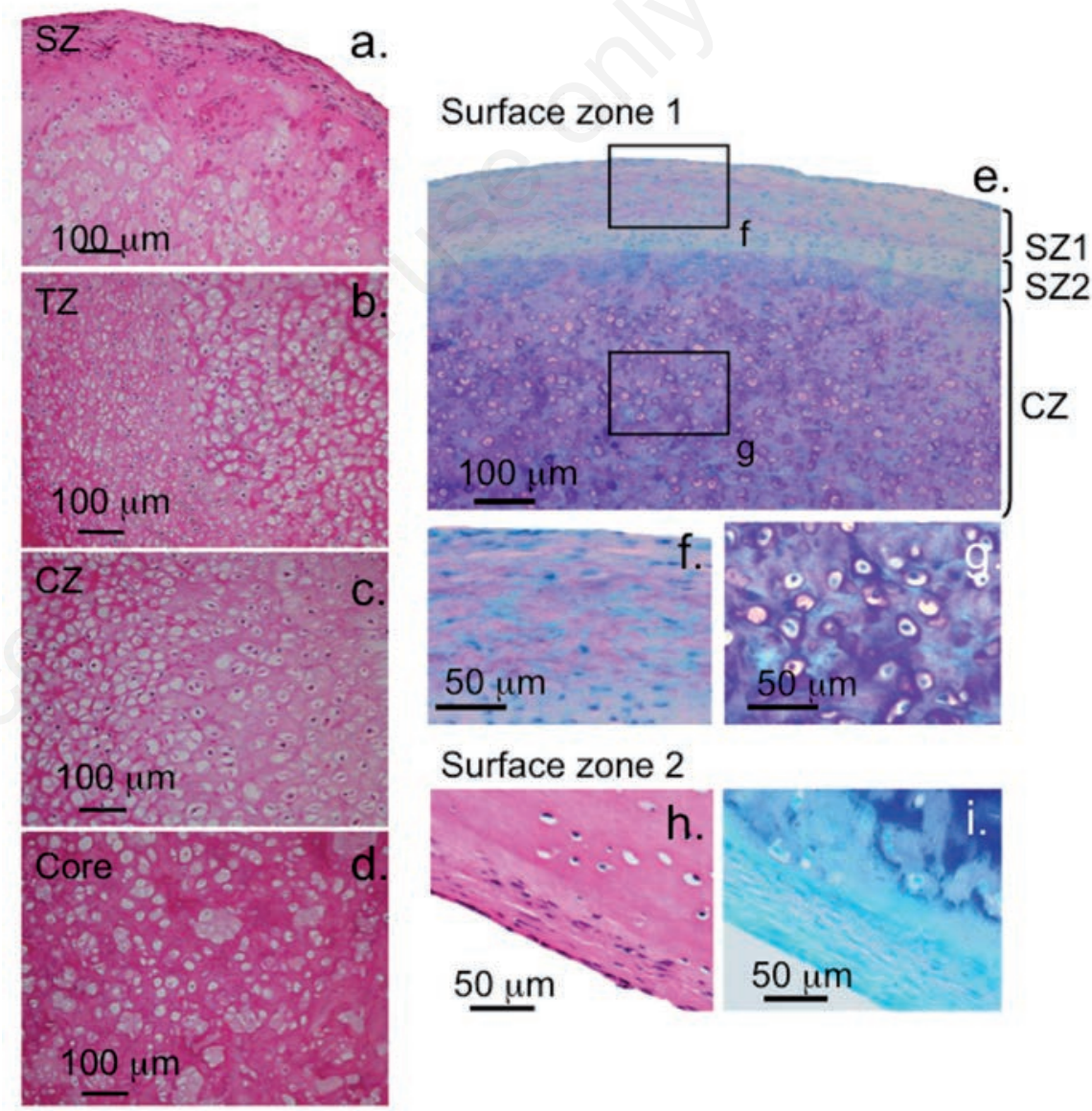

\section{Surface zone 2}

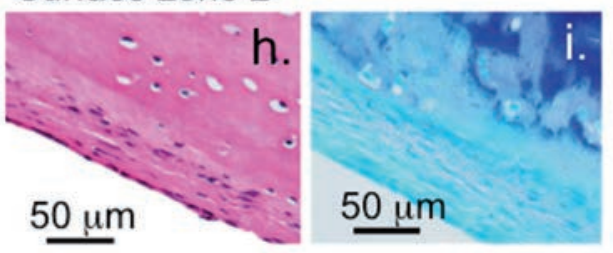

Figure 2. Cellular morphologies of selected regions of the loose body depicted in Figure 1. H\&E stained loose body tissue sections depicting cellular morphology; (a) the surface zone (SZ) cells are small and of a flattened morphology and are located adjacent to the transitional zone (TZ) where better defined rounded cells are located (b), this leads into the cartilaginous zone (CZ) where the cells are larger again (c) and reminiscent of cells in the cartilage rudiments in human foetal joint development. The cells of the core region (d) are somewhat mishapen and many are dead and arranged in clumps. Toluidine blue-fast green and H\&E stained loose body sections of surface zones 1 and 2 (see Figure 1) of the loose body (a-e). Two surface zone areas can be differentiated on the basis of cellular distributions (SZ1, SZ2) and GAG staining (e). The cells in the cartilaginous zone (CZ) are larger, rounded and surrounded by a matrix containing toluidine blue stained proteoglycan. The surface zone cells have differing morphologies to the deeper chondrocytic cells and do not lay down as high levels of proteoglycan as the CZ cells $(f, g, h, i)$. 
ies in the knee joint and could be of further application. We initially examined the cells isolated by flow cytometry, front and side scatter data demonstrated a single cell population with only a small proportion of dead or nonviable cells. Loose body cell numbers were initially expanded in monolayer culture which eliminated these dead cells and demonstrated a homogeneous cell population of cells with a typical cobblestone morphology and of high replicative capability and viability. Further culture of these cells encapsulated in alginate microspheres allowed us to demonstrate the synthesis of type II collagen, aggrecan, and KS but not of type I collagen by the loose body cells. Chondrocytes do not divide in this culture system but produce cartilage specific ECM components. The lack of type I collagen synthesis was further evidence of the chondrocytic pedigree of the isolated cell population. Furthermore morphometric image analysis of the immunolocalised bead sections over a 2-8 week culture period demonstrated a steady increase in chondrocyte ECM products plateauing at 4 weeks of culture. Our laboratory has formerly used this culture system with intervertebral disc cells, meniscal cells and articular chondrocytes..$^{11,13,14,18-20}$

The microcarrier cell culture system was first introduced in 1967 by van Wezel..$^{21}$ These spheres were typically $125-250 \mu \mathrm{m}$ in size and made from DEAE-dextran, bioglass, polystyrene, acrylamide, collagen or alginate and were available commercially as dextran beads (Cytodex, GE Healthcare), alginate (GEM, Global Cell Solutions), collagen (Cultispher, Percell) and polystyrene (Solohill Engineering). The surface chemistries of these microspheres were conducive to cell attachment and they were robust enough for use in spinner cultures. Cancer cells were one cell type which was cultured on and within these spheres in an effort to simulate a spheroid cell mass and promote cellular cross-talk to maintain cell viability and provide a culture system suitable for the assessment of anti-cancer agents in vitro. ${ }^{22,23}$ In 1992 alginate microspheres were developed as an encapsulated system for the culture of cells of a chondrogenic background. ${ }^{24,25}$ The high negative charge of the mannuronic and guluronic acid alginate copolymer was envisaged to reproduce the high fixed charge density 3D microenvironment chondrocytes experience in cartilaginous matrices. Chondrocytes rarely undergo division when surrounded by a mature 3D ECM however with maturity terminal differentiation can lead to hypertrophy. Neither of these features were displayed by the loose body chondrocytes in the alginate bead cultures examined in the present study (Figures 3 and 4) however these features were evident in histological sections of the loose bodies and typical of the columnar arrangement of growth plate chondrocytes (Figures 1 and 2) suggesting that the loose bodies may also be useful as models of the growth plate. The deer antler has been suggested as a growth plate model, mainly stemming from its impressive rate of growth however deer antler has a tissue organisation quite dissimilar to that of the long bone growth plates ${ }^{26,27}$ whereas, as seen in the present study, loose bodies have similar cellular arrangements to these found in growth plate cartilage. Loose bodies can be stored in standard tissue culture media containing foetal calf serum and antibiotics to maintain cell viability for at least 3 weeks making them a potentially useful research tool and they could be considered as explants without cut edges. In the present study, the distribution of chondrocytes in alginate beads and absence of cell division were well illustrated in the negative control bead sections (Figure $4 \mathrm{~h}$ ). Long term culture (8 months) of chondrocytes in alginate beads have been reported to lead to morphological changes in the outer bead cells with the appearance of cells of a flattened morphology similar to annular fibrochondrocytes in the intervertebral disc, whereas cells located more centrally within the bead have well

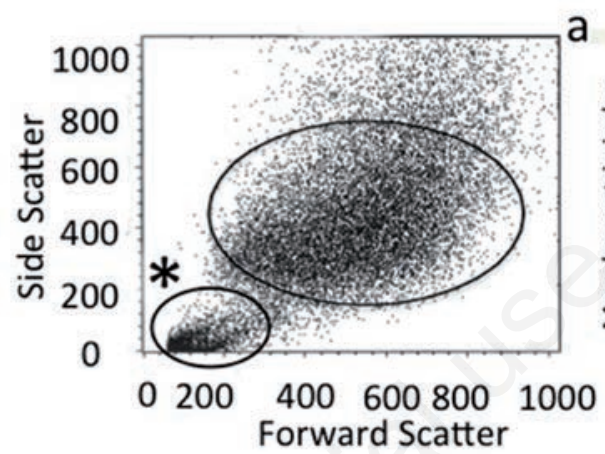

a
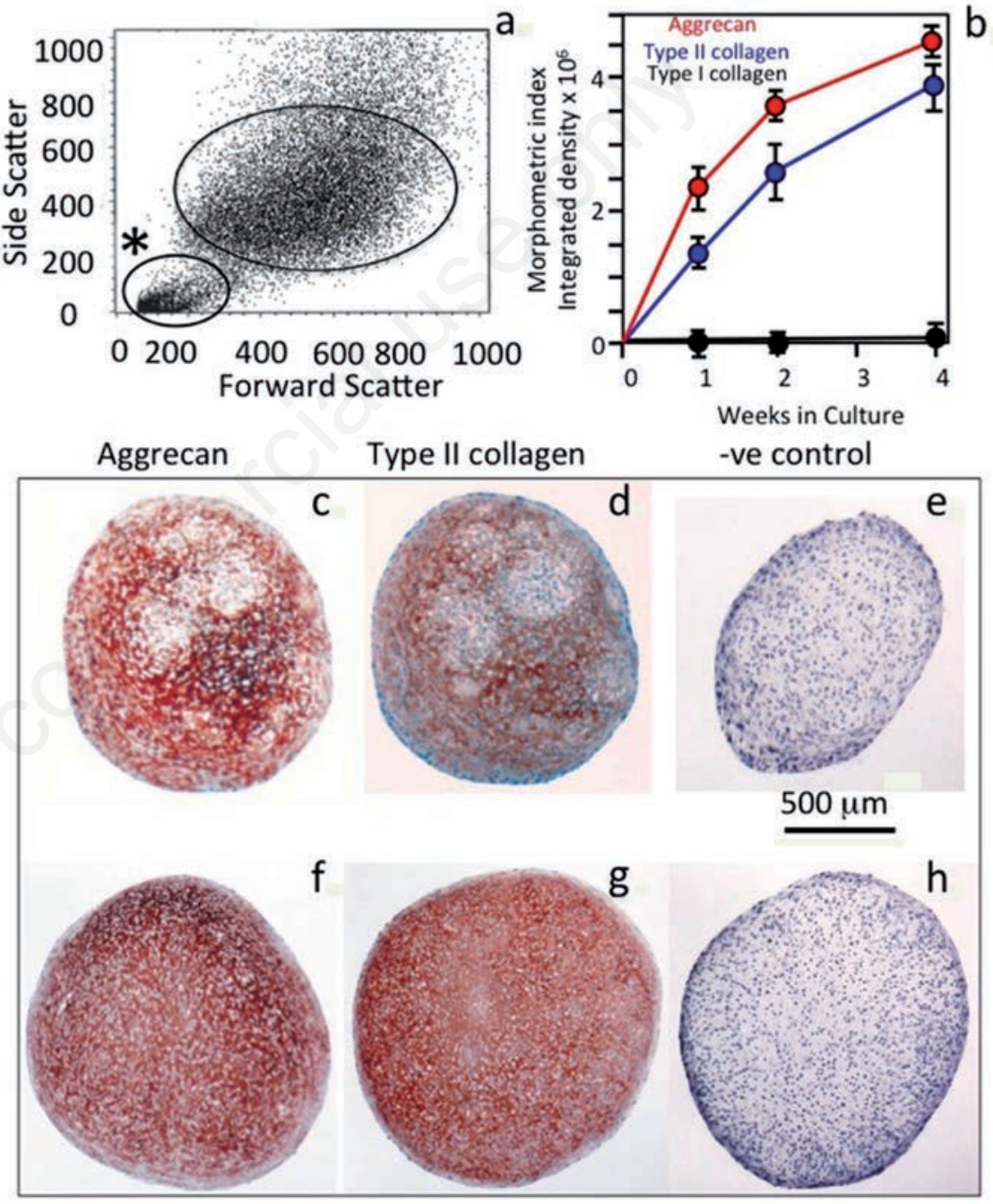

Figure 3. Assessment of the polydispersity of the loose body cell preparation isolated in this study and morphometric image analysis of staining intensities of individual beads stained with antibodies to aggrecan, type I, II collagen in alginate bead culture. a) Flow cytometric analysis of the loose body cell preparation isolated by front and side scatter characteristics; the gated area labelled with an asterisk designates dead or non-viable cells. b) Immunolocalised Collagen I, II and aggrecan in bead sections from 2, 3 and 4 weeks of culture ( 4 beads per time point) were subjected to morphometric image analysis to quantitate the staining using Adobe Photoshop software. Integrated density of the stained pixels were measured, data shown is $x$ 106. Immunolocalisation of aggrecan $(c, f)$ and type II collagen $(\mathrm{d}, \mathrm{g})$ in sections of beads from 2 and 3 weeks of alginate bead culture. 
defined rounded chondrocytic morphologies. ${ }^{28}$

A re-evaluation of the microsphere culture system has occurred in the last few years where cancer cells are encapsulated in an environment permissive to cell-cell cross-talk. Various matrix components can also be introduced into the bead in an effort to develop a more appropriate cell culture micro-environment similar to that found in vivo. ${ }^{22,29-34}$ This culture system has been used to culture macrophages and fibroblasts in breast cancer, ${ }^{35}$ invasive hepatocellular cells, ${ }^{32}$ and epithelial-stromal cells in prostate cancer. ${ }^{36}$ Porous chitosan-alginate microspheres have also been developed to examine prostate cancer $^{37}$ and glioma. ${ }^{38}$ Hepatocarcinoma spheroids have also been prepared using gelatin microspheres. ${ }^{39}$ Pullulan $^{40}$ and controlled release rhBMP2 in 3D printed porous hydroxyapatite, ${ }^{41}$ injectable nanofibrous microspheres, ${ }^{41}$ and arginine-chitosan BMP-2 nanoparticle cell delivery vehicles for bone repair have also been developed. . $^{32,33}$

These promising initial findings with the loose body chondrocytes warrants further studies to determine the gene expression profiles of the loose body chondrocytes compared to articular and growth plate chondrocytes.
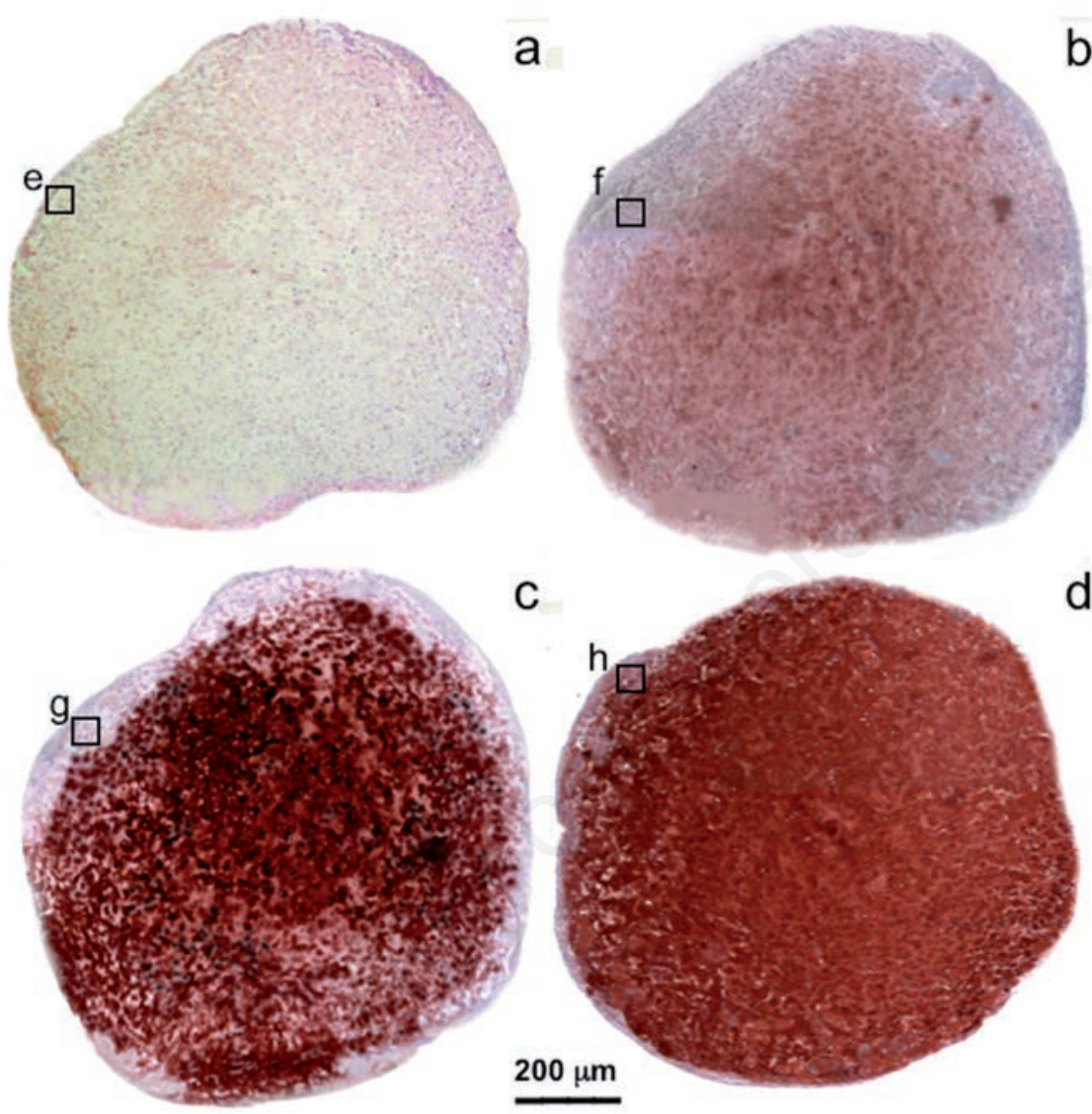

C
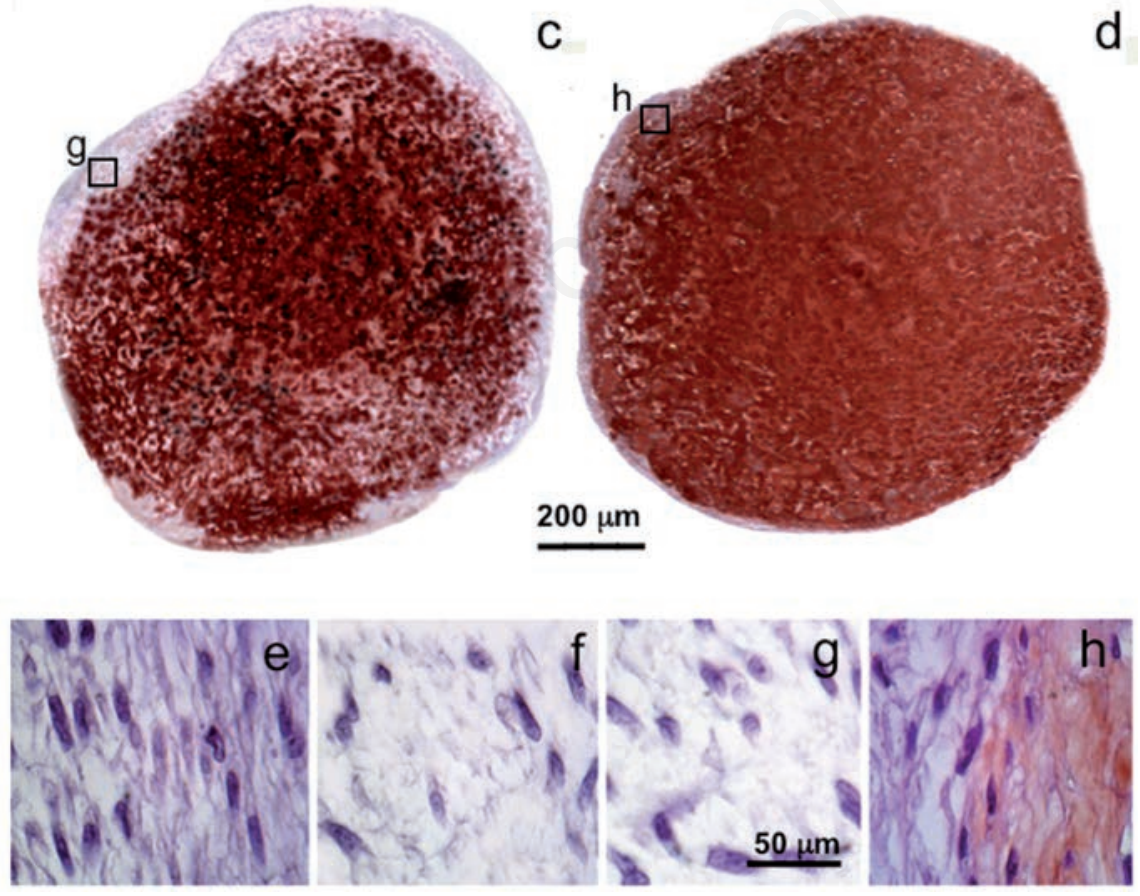

Figure 4. Immunolocalisation of type I collagen (a), type II collagen (b), aggrecan (c) and KS (d) in sections of alginate beads of the loose body chondrocytes after 4 weeks of culture. The outer zone cells (e-h) had a more flattened morphology than the central bead cells this has also been observed in long-term bead cultures with intervertebral disc cells. The central bead cells expressed a chondrogenic phenotype synthesising type II collagen, aggrecan and KS but no type I collagen. A low level of type I collagen was evident with the more flattened outer bead cells (h).
Human chondrocytes are difficult to source and it is only relatively recently that knee chondrocytes have become available commercially with most suppliers previously using hip cartilage as a tissue source. Pascual-Garrido et $a l .{ }^{42}$ found the viability of loose bodies from paediatric patients were $88 \%$ vs $92 \%$ for healthy articular cartilage. Others have also suggested that the loose body cells represent a valuable resource for autologous cell transplantation. ${ }^{43}$ Thus, the loose bodies examined in the present study should be considered a valuable cell resource rather than as a surgical discard.

\section{References}

1. Mutlu H, Silit E, Pekkafali Z, Karaman B, Omeroglu A, Basekim CC et al. Multiple rice body formation in the subacromialsubdeltoid bursa and knee joint. Skeletal Radiol 2004;33:531-3.

2. Willis RB, Firth G. Traumatic patellar dislocation: loose bodies and the MPFL. J Pediatr Orthop 2012;32:S47-51.

3. Boden RA, Razak A, Hussain SM, McLoughlin SJ Loose body following crosspin fixation for anterior cruciate ligament reconstruction. J Orthop Traumatol 2013; 14:155-7.

4. Cossey AJ, Paterson RS. Loose intra-articular body following anterior cruciate ligament reconstruction. Arthroscopy 2005;21: 348-50.

5. Macdonald P, Arneja S. Biodegradable screw presents as a loose intra-articular body after anterior cruciate ligament reconstruction. Arthroscopy 2003;19:E22-4.

6. Ohishi T, Takahashi M, Matsuyama Y, Osteochondritis dissecans with a large osteochondral free body in the posterolateral compartment of the knee: a case report. Knee 2014;21:620-3.

7. Tahmasebi MN, Bashti K, Sobhan M, Ghorbani G. Bilateral synovial knee chondromatosis in a patient with rheumatoid arthritis: case-report and literature review. Arch Bone J Surg 2014;2:260-4.

8. Sourlas I, Brilakis E, Mavrogenis A, Stavropoulos N, Korres D. Giant intraarticular synovial osteochondromata of the knee. Hippokratia 2013;17:281-3.

9. Wheeldon G, Altiok H. Dysplasia epiphysealis hemimelica of the knee: an unusual presentation with intra-articular loose bodies and literature review. J Pediatr Orthop B 2015;24:326-9.

10. Melrose J, Smith S, Cake M, Read R, Whitelock J. Comparative spatial and temporal localisation of perlecan, aggrecan and type I, II and IV collagen in the ovine 
meniscus: an ageing study. Histochem Cell Biol 2005;124:225-35.

11. Melrose J, Smith S, Ghosh P. Assessment of the cellular heterogeneity of the ovine intervertebral disc: comparison with synovial fibroblasts and articular chondrocytes. Eur Spine J 2003;12:57-65.

12. Smith, S. M., Shu, C. \& Melrose, J. Comparative immunolocalisation of perlecan with collagen II and aggrecan in human foetal, newborn and adult ovine joint tissues demonstrates perlecan as an early developmental chondrogenic marker. Histochem Cell Biol 2010; 134: 251-263.

13. Melrose J, Smith S, Ghosh P. Differential expression of proteoglycan epitopes by ovine intervertebral disc cells. J Anat 2000;197:189-98.

14. Melrose J, Smith S, Ghosh P, Taylor TK. Differential expression of proteoglycan epitopes and growth characteristics of intervertebral disc cells grown in alginate bead culture. Cells Tissues Organs 2001;168:137-46.

15. Horas U, Pelinkovic D, Herr G, Aigner T, Schnettler R. Autologous chondrocyte implantation and osteochondral cylinder transplantation in cartilage repair of the knee joint. A prospective, comparative trial. J Bone Joint Surg Am 2003;85:185-192.

16. Nazempour A, Van Wie BJ. Chondrocytes, Mesenchymal stem cells, and their combination in articular cartilage regenerative medicine. Ann Biomed Eng 2016;44:1325-54.

17. Vedicherla S, Buckley CT. Cell-based therapies for intervertebral disc and cartilage regeneration - current concepts, parallels and perspectives. J Orthop Res 2016 doi:10.1002/jor.23268. [Epub ahead of print].

18. Collier S, Ghosh P. Effects of transforming growth factor beta on proteoglycan synthesis by cell and explant cultures derived from the knee joint meniscus. Osteoarthritis Cartilage 1995;3:127-38.

19. Little CB, Ghosh P. Variation in proteoglycan metabolism by articular chondrocytes in different joint regions is determined by post-natal mechanical loading. Osteoarthritis Cartilage 1997;5:49-62.

20. Pattison ST, Melrose J, Ghosh P, Taylor TK. Regulation of gelatinase-A (MMP-2) production by ovine intervertebral disc nucleus pulposus cells grown in alginate bead culture by Transforming Growth Factorbeta(1)and insulin like growth factor-I. Cell Biol Int 2001;25:679-89.

21. van Wezel AL. Growth of cell-strains and primary cells on micro-carriers in homoge- neous culture. Nature 1967;216:64-5.

22. Godugu C, Patel AR, Desai U, Andey T, Sams A, Singh M. AlgiMatrix ${ }^{\mathrm{TM}}$ based 3D cell culture system as an in-vitro tumor model for anticancer studies. PLoS One 2013;8:e53708.

23. Lan SF, Starly B. Alginate based 3D hydrogels as an in vitro co-culture model platform for the toxicity screening of new chemical entities. Toxicol Appl Pharmacol 2011;256:62-72.

24. Maldonado BA, Oegema TR Jr. Initial characterization of the metabolism of intervertebral disc cells encapsulated in microspheres. J Orthop Res 1992;10: 677-90.

25. Tamponnet C, Ramdi H, Guyot JB, Lievremont M. Rabbit articular chondrocytes in alginate gel: characterisation of immobilized preparations and potential applications. Appl Microbiol Biotechnol 1992;37:311-5.

26. Price JS, Oyajobi B0, Nalin AM, Frazer A, Russell RG, Sandell LJ. Chondrogenesis in the regenerating antler tip in red deer: expression of collagen types I, IIA, IIB, and $\mathrm{X}$ demonstrated by in situ nucleic acid hybridization and immunocytochemistry. Dev Dyn 1996;205:332-47.

27. Rucklidge GJ, Milne G, Bos KJ, Farquharson C, Robins SP. Deer antler does not represent a typical endochondral growth system: immunoidentification of collagen type $\mathrm{X}$ but little collagen type II in growing antler tissue. Comp Biochem Physiol B Biochem Mol Biol 1997;118:303-8.

28. Häuselmann HJ1, Fernandes RJ, Mok SS, Schmid TM, Block JA, Aydelotte MB, et al. Phenotypic stability of bovine articular chondrocytes after long-term culture in alginate beads. J Cell Sci 1994;107:17-27.

29. Estrada MF, Rebelo SP, Davies EJ, Pinto MT, Pereira H, Santo VE, et al. Modelling the tumour microenvironment in longterm microencapsulated 3D co-cultures recapitulates phenotypic features of disease progression. Biomaterials 2016;78: 50-61.

30. Godugu C, Singh M. AlgiMatrix-based 3D cell culture system as an in vitro tumor model: an important tool in cancer research. Methods Mol Biol 2016;1379: 117-28.

31. Wang Y, Wang J. Mixed hydrogel beadbased tumor spheroid formation and anticancer drug testing. Analyst 2014;139 2449-58.

32. Xu XX, Liu C, Liu Y, Li N, Guo X, Wang SJ, et al. Encapsulated human hepatocellular carcinoma cells by alginate gel beads as an in vitro metastasis model. Exp Cell Res 2013;319:2135-44.

33. Xu XX, Liu C, Liu Y, Yang L, Li N, Guo X, et al. Enrichment of cancer stem cell-like cells by culture in alginate gel beads. J Biotechnol 2014;177:1-12.

34. Yu L, Ni C, Grist SM, Bayly C, Cheung KC. Alginate core-shell beads for simplified three-dimensional tumor spheroid culture and drug screening. Biomed Microdevices 2015;17:33.

35. Rama-Esendagli D, Esendagli G, Yilmaz G, Guc D. Spheroid formation and invasion capacity are differentially influenced by co-cultures of fibroblast and macrophage cells in breast cancer. Mol Biol Rep 2014;41:2885-92.

36. Fang X, Sittadjody S, Gyabaah K, Opara EC, Balaji KC. Novel 3D co-culture model for epithelial-stromal cells interaction in prostate cancer. PLoS One 2013;8:e75187.

37. Florczyk SJ, Liu G, Kievit FM, Lewis AM, Wu JD, Zhang M. 3D porous chitosan-alginate scaffolds: a new matrix for studying prostate cancer cell-lymphocyte interactions in vitro. Adv Healthc Mater 2012;1:590-99.

38. Kievit FM, Florczyk SJ, Leung MC, Veiseh 0, Park J0, Disis ML, et al. Chitosan-alginate 3D scaffolds as a mimic of the glioma tumor microenvironment. Biomaterials 2010;31:5903-10.

39. Leong W, Kremer A, Wang DA. Development of size-customized hepatocarcinoma spheroids as a potential drug testing platform using a sacrificial gelatin microsphere system. Mater Sci Eng C Mater Biol Appl 2016;63 644-9.

40. Aydogdu H, Keskin D, Baran ET, Tezcane, A. Pullulan microcarriers for bone tissue regeneration. Mater Sci Eng C Mater Biol Appl 2016;63:439-49.

41. Wang H, Wu G, Zhang J, Zhou K, Yin B, Su $\mathrm{X}$, et al. Osteogenic effect of controlled released rhBMP-2 in 3D printed porous hydroxyapatite scaffold. Colloids Surf B Biointerfaces 2016;141:491-8.

42. Pascual-Garrido C, Tanoira I, Muscolo DL, Ayerza MA, Makino A. Viability of loose body fragments in osteochondritis dissecans of the knee. A series of cases. Int Orthop 2010;34:827-31.

43. Giannini S, Buda R, Grigolo B, Vannini F, De Franceschi L, Facchini A. The detached osteochondral fragment as a source of cells for autologous chondrocyte implantation (ACI) in the ankle joint. Osteoarthritis Cartilage 2005;13:601-7. 